\title{
Prevalence and Burden of Dyspnoea Among Patients with Chronic Obstructive Pulmonary Disease in Five European Countries
}

\author{
Yogesh Suresh Punekar (D) Hana Mullerova • Mark Small • \\ Tim Holbrook · Robert Wood · Ian Naya · Manuel Valle
}

Received: November 26, 2015 / Published online: February 19, 2016

(C) The Author(s) 2016. This article is published with open access at Springerlink.com

\begin{abstract}
Introduction: Dyspnoea is a common symptom of chronic obstructive pulmonary disease (COPD) that has a significant direct impact on patients' respiratory health status and contributes substantially to the economic burden of the disease. The objective of this
\end{abstract}

Enhanced content for this article can be found at http:// www.medengine.com/Redeem/8244F06016CEDF73.

Electronic supplementary material The online version of this article (doi:10.1007/s41030-016-0011-5) contains supplementary material, which is available to authorized users.

Y. S. Punekar $(\bowtie)$

Value Evidence and Outcomes, GlaxoSmithKline R\&D, Uxbridge, UK

e-mail: yogesh.q.punekar@gsk.com

H. Mullerova

Worldwide Epidemiology, GlaxoSmithKline R\&D, Uxbridge, UK

M. Small · T. Holbrook · R. Wood Adelphi Real World, Macclesfield, UK

I. Naya

Respiratory Medical, GlaxoSmithKline, Uxbridge, UK

M. Valle

Pneumology Department, Hospital Universitario Puerta de Hierro, Majadahonda, Madrid, Spain study was to report on the prevalence of dyspnoea and its cost impact among patients with COPD in five European countries (France, Germany, Italy, Spain and the UK).

Methods: A population-based cross-sectional survey (Respiratory Disease-Specific Programme, Adelphi Real World) was conducted among 2531 patients with COPD and their treating physicians. Information was collected on demographic and clinical characteristics, dyspnoea [modified Medical Research Council (mMRC) scale], health status [COPD Assessment Test (CAT), EuroQol (EQ-5D-3L)], sleep [Jenkins Sleep Evaluation Questionnaire (JSEQ)], and healthcare resource use including moderate-to-severe COPD exacerbations, physician visits, COPD medications, and other COPD-related resources. The humanistic and economic burden was derived from two cohorts based on their level of dyspnoea (mMRC $<2$ vs. $m M R C \geq 2$ ) who were matched by propensity scores to balance their demographic and disease burden characteristics.

Results: Moderate-to-severe dyspnoea (mMRC $\geq 2$ ) was highly prevalent across all countries, ranging from $39.5 \%$ in France to $60.2 \%$ in the UK. Overall in the unmatched cohorts, mMRC $\geq 2 \quad(n=1199)$ was associated with more 
comorbidities and more frequent exacerbations ( $\geq 2 /$ year) compared to patients with $\mathrm{mMRC}<2$ $(n=1332)$. Descriptive analysis indicated that the patient cohort with worse dyspnoea had poorer health status (CAT: 25.1 vs. 16.2; $P<0.0001$ ), poorer sleep (JSEQ: 7.1 vs. 3.8 ; $P<0.0001)$, and poorer quality of life (EQ-5D-3L: 0.66 vs. $0.88 ; P<0.0001$ ). These findings were replicated in each of the five $\mathrm{EU}$ countries. In the propensity score-matched population balanced for non-dyspnoeic severity parameters, patients with worse dyspnoea had significantly higher annual costs for COPD management ( $€ 4372$ vs. $€ 2031, P<0.0001)$.

Conclusion: Moderate-to-severe dyspnoea is highly prevalent in patients with COPD across the five European countries studied. It is associated with a significant disease burden and more than doubles the economic burden on health care systems.

Funding: GlaxoSmithKline (Study number HO-15-15223).

Keywords: Chronic obstructive pulmonary disease (COPD); Costs; Dyspnoea; Prevalence; Resource use

\section{INTRODUCTION}

Chronic obstructive pulmonary disease (COPD) is characterized by persistent, usually progressive, airflow limitation [1]. COPD is a major cause of chronic morbidity and mortality, and presents a significant health challenge to payers across the world [2]. Despite being a preventable and treatable condition, COPD remains the third leading cause of death in the world [3].

Dyspnoea, commonly known as breathlessness, is the most common symptom of COPD [4]. An increase in the level of dyspnoea is associated with an increase in fatigue and disability [5]. Dyspnoea has also been shown to be associated with a decrease in health-related quality of life [6]. However, cultural dimensions such as differences in language, race, ethnicity, and gender can influence the interpretation, quality, and intensity of reported dyspnoea [7]. Whilst there is evidence showing that higher levels of dyspnoea are associated with an increased risk of a COPD exacerbation and mortality, there is limited evidence reporting the healthcare resource use (HCRU) among patients with differing levels of dyspnoea for the majority of countries $[8,9]$.

The objective of this study was to report the prevalence of moderate-to-severe dyspnoea and explore its humanistic and economic impact among patients with stable COPD across Europe and within individual European countries.

\section{METHODS}

\section{Survey Design and Study Population}

The Respiratory Disease-Specific Programme (DSP; Adelphi Real World) is a survey which collects key health outcomes information from patients diagnosed with COPD routinely consulting with their treating physicians. The full methodology of the DSP has been described previously [10].

Briefly, the DSP involves two key phases. First, physicians are randomly selected by members of a local research agency in each country from public lists of healthcare professionals practicing in primary care or respiratory specialty as appropriate. These physicians are representative of the national population of physicians in terms of the physician's age, gender, and volume of activity, and are selected based on the quotas set by specialty type, geographical location, and 
number of patients with COPD currently being treated by them. For this study, data were combined from three separate Respiratory DSP surveys (2010, 2011, and 2012) conducted in five European countries: France, Germany, Italy, Spain, and the UK. Each survey was administered to approximately 500 physicians [50 primary care physicians (PCPs) and 50 pulmonologists per country].

The second phase involved physicians completing a standardized record form on the next six consenting patients diagnosed with COPD visiting their practice. Patients were selected by physicians based on consecutive sampling meeting the inclusion criteria of more than 40 years of age with history of smoking and diagnosis of airflow obstruction (COPD, emphysema, and/or chronic bronchitis) irrespective of their reason for physician visit such as repeat prescription, routine review, or an unscheduled consultation. The physician-completed record forms were completed only for the patients personally seen by the physician either during or immediately after the consultation by referring to patient records if needed. The physician-completed record form collected information on patient demographics, diagnostic history, and resource use in the past 12 months, current symptomatology and its impact on lifestyle, current and past treatments, treatment adherence, comorbidities [11], and inhaler preference. Of these, data on resource use in the previous 12 months and the treatments patients were prescribed at the time of the survey were used in the present analysis.

Patients for whom a record form had been completed were then asked to complete a separate patient self-completion questionnaire by their physicians in clinic immediately after the physician visit. Representatives of the data collection agency ensured that patients completed their questionnaire without consulting the doctor, nursing staff, or any other individual. Patients completed information on their COPD history, current symptomatology and its impact on general and COPD-specific health status, current treatments, and attitude towards COPD and its treatment. They also provided information on their health status at the time of the survey using a series of validated patient-reported outcome tools. This included disability due to dyspnoea captured using the modified Medical Research Council (mMRC) scale [12], COPD-related health status using the COPD Assessment Test (CAT) [13], general health status using the EuroQol questionnaire (3 levels; EQ-5D-3L) [14], sleep quality based on the Jenkins Sleep Evaluation Questionnaire (JSEQ) [15], and medication adherence using the Morisky Medication Adherence Scale (MMAS) [16].

\section{Patient Inclusion Criteria}

All patients included in this analysis were 40 years or older with a physician-confirmed diagnosis of airflow obstruction (COPD, emphysema, and/or chronic bronchitis). The patients were also required to have received at least one short- or long-acting COPD-specific treatment in the previous 12 months and were required to have a completed response to the mMRC scale question from the patient-completed questionnaire.

The survey was conducted as a market research survey adhering to the ICC/ESOMAR international code on market and social research [17] and, therefore, ethical approval was not sought. Our study was a retrospective analysis of secondary data. Prior to volunteering to complete a questionnaire patients were asked to provide informed consent. The survey instructions described the purpose of the survey, why the respondent had been selected, and who might have access to the aggregated and anonymized dataset compiled. 


\section{Study Outcomes and Their Derivation}

Patients were stratified by their level of dyspnoea at the time of the survey as no-to-mild $(\mathrm{mMRC}<2)$ or moderate-to-severe (mMRC $\geq 2$ ) dyspnoea [1]. For each of these strata, patients' current humanistic burden was captured using CAT, JSEQ, and EQ-5D-3L. Utilities were calculated using country-specific valuation sets of EQ-5D-3L. Utilities were defined as cardinal values that reflect an individual's preferences for different health outcomes [18]. Thus, EQ-5D-3L utilities in each country represents preferences of general public for different health outcomes. The resource use over the previous 12 months was estimated using data collected in the physician-completed patient form. It included primary and secondary care consultations, moderate and severe exacerbations, visits to emergency departments, COPD- and non-COPD-related hospital stay, as well as COPD-related medications. Mean estimates for each resource use were derived for each country separately and were then converted to costs using appropriate unit cost for each event (see Table S1 in the supplementary material).

The unit costs were obtained from the literature or from a local expert specializing in health economics [19-32]. If multiple costs were available, the lowest cost was used as a conservative estimate. Exacerbation costs were calculated by combining the cost of treating a moderate exacerbation with the cost of prednisolone (40 mg once daily) treatment for 5 days if treated with an oral corticosteroid and/ or the cost of co-amoxiclav treatment $(875 \mathrm{mg}$ / $125 \mathrm{mg}$ twice daily) for seven days if treated with an antibiotic. Country-specific unit costs for each class of COPD treatment were generated by averaging the unit costs of the top five (or less) selling products (in units) within that class for each country. The total medication cost in a therapy class was then estimated by multiplying the number of prescriptions in the last 12 months for that class (currently or previously received) by the unit cost estimated based on sales. Missing prescription data were imputed per country based on the average number of prescriptions per week for that class.

\section{Data Analysis}

To report the burden of dyspnoea at the European level, patients across individual countries (France, Germany, Italy, Spain, and the UK) were pooled to form a single cohort. Further, the pooled cohort was weighted to ensure that the sample was more representative of the patient population. Weighting was based on an inverse probability of the patients' 12-month consultation rate. For patients with less than 12 months of consultation history, this weight was imputed based on their available consultations and the length of time the patient has been managed by the physician. Weightings were not applied to multivariate analyses.

Patients were described using demographic and healthcare utilization descriptors by their level of dyspnoea as no-to-mild $(\mathrm{mMRC}<2)$ and moderate-to-severe (mMRC $\geq 2$ ). For each of these strata, the humanistic burden at the time of the survey was estimated using CAT, JSEQ, and EQ-5D-3L. The economic burden based on physician-reported HCRU also was estimated for the two dyspnoea-based cohorts. Statistical differences in humanistic and economic burden between groups (mMRC $<2$ vs. $m M R C \geq 2$ ) were assessed using appropriate weighted regression models, whereby the type of regression model used depended on the type or distribution of the outcome variable. A significance level of 0.05 was used. 
Finally, the two cohorts $(\mathrm{mMRC}<2$ vs. mMRC $\geq 2$ ) were matched using propensity score matching techniques [33]. Patients with moderate-to-severe dyspnoea were matched to a cohort of patients with no-to-mild dyspnoea with replacement to produce closely matched profiles [34, 35]. Covariates included in the matching were age, gender, smoking status, time since diagnosis, use of inhaled corticosteroid (ICS)-containing regimens including triple therapy, exacerbation history, number of concomitant conditions, and presence of severe cardiovascular comorbidity (Table 1). Propensity scores were generated using logistic regression models. Standardized mean differences (SMDs) were used to assess covariate balance once the matching was complete. An SMD between $-10 \%$ and $10 \%$ (not inclusive) indicates adequate balance was achieved for that particular covariate [34]. To compare the total annual COPD management costs across two subgroups post-matching, the Abadie-Imbens (AI) standard error (SE) was estimated and the corresponding test statistic and $P$ value were calculated $[36,37]$. The effect of unobserved confounders on the $P$ value was assessed using Rosenbaum sensitivity analyses [38]. In addition to the total cohort, this propensity matching analysis was also conducted in sub-cohorts of patients treated with mono-bronchodilators, ICS/long-acting $\beta$-agonist (LABA) fixed-dose combinations, and triple therapy [long-acting muscarinic antagonists (LAMA) + ICS + LABA or LAMA + ICS/LABA]. Analyses were conducted using Stata v13.0 (StataCorp LP, College Station, TX, USA) and $\mathrm{R}$ v3.0 (R Foundation for Statistical Computing, Vienna, Austria).

Table 1 Patient disposition and demographic characteristics

\begin{tabular}{|c|c|c|c|c|c|}
\hline \multirow[t]{2}{*}{ Patient variable } & \multicolumn{2}{|l|}{ All patients } & \multicolumn{3}{|c|}{ Propensity score-matched cohort } \\
\hline & $\begin{array}{l}\mathrm{mMRC}<2 \\
(n=1332)\end{array}$ & $\begin{array}{l}\mathrm{mMRC} \geq 2 \\
(n=1199)\end{array}$ & $\begin{array}{l}\mathrm{mMRC}<2 \\
\left(n=762^{\mathrm{a}}\right)\end{array}$ & $\begin{array}{l}\mathrm{mMRC} \geq 2 \\
(n=762)\end{array}$ & $\begin{array}{l}\text { SMD } \\
(\%)\end{array}$ \\
\hline Age in years, mean $(S D)^{b}$ & $62.8(9.9)$ & $68.4(9.2)$ & 66.9 & 67.5 & 6.3 \\
\hline Gender, male & $914(70.9)$ & $849(71.7)$ & $566(74.3)$ & $543(71.3)$ & -6.7 \\
\hline Time since diagnosis in months, mean $(S D)^{b}$ & $67.3(52.3)$ & $92.2(75.7)$ & 89.1 & 90.8 & 2.3 \\
\hline Ex-smokers $^{c}$ & $832(64.4)$ & $835(73.7)$ & $531(69.7)$ & $530(69.6)$ & -0.3 \\
\hline Currently on ICS treatment ${ }^{\mathrm{b}}$ & $750(51.5)$ & $828(69.9)$ & $542(71.1)$ & $534(70.1)$ & -2.3 \\
\hline Triple therapy ${ }^{\mathrm{b}}$ & $374(26.6)$ & $567(49.0)$ & $338(44.4)$ & $357(46.9)$ & 5.0 \\
\hline $2+$ exacerbations, prior year ${ }^{b}$ & $272(16.9)$ & $576(44.3)$ & $382(50.1)$ & $386(50.7)$ & 1.0 \\
\hline Number of comorbidities, mean $(S D)^{b}$ & $0.8(1.0)$ & $1.3(1.4)$ & 1.3 & 1.3 & 3.2 \\
\hline Serious CV comorbidity ${ }^{\mathrm{b}}$ & $302(22.1)$ & $550(48.2)$ & $351(46.1)$ & $352(46.2)$ & 0.3 \\
\hline
\end{tabular}

Results are presented as $n$ (\%) unless otherwise stated

Results for all patients are based on weighted analyses and those for propensity-matched cohort were based on unweighted data

$C V$ cardiovascular, ICS inhaled corticosteroids, $m M R C$ Modified Medical Research Council dyspnoea scale, $S D$ standard deviation, $S M D$ standardized mean difference

a Consists of 400 unique patients

b $P<0.0001$

c $P=0.0002$ 


\section{RESULTS}

A total of 2531 patients with COPD across five European countries (France, Germany, Italy Spain, and the UK) were included in this study. The mean age of this cohort was 65.4 years and $28.7 \%$ were female. The mean time since COPD diagnosis was 6.6 years and approximately a third (31.2\%) were continuing smokers. Most patients (60.2\%) received an ICS-containing treatment with $37.2 \%$ on triple therapy (ICS/LABA + LAMA). The mean number of concomitant conditions for this cohort was 1.1 (standard deviation: 1.2) with approximately a third (34.5\%) suffering with serious cardiovascular comorbidity.

\section{Prevalence of Dyspnoea}

Nearly half of the patients $(47.3 \%)$ reported a moderate-to-severe level of dyspnoea $(m M R C \geq 2)$. The frequency of dyspnoea ranged from $39.5 \%$ in France to $60.2 \%$ in the UK (Fig. 1). This was validated using a sample of respondents, 40 years or older and receiving respiratory medications, collected as part of Health Survey of England [39]. The analysis showed that $56 \%$ of respondents indicated that their condition affects their stamina, breathing, or fatigue. Patients with dyspnoea were older, had a longer duration of diagnosed COPD, and more comorbidities in the combined cohort (Table 1). A higher proportion of patients with dyspnoea were ex-smokers, currently received ICS-containing medications including triple therapy and suffered from a serious cardiovascular condition.

\section{Association of Dyspnoea Level with Health Status}

Moderate-to-severe dyspnoea was significantly associated with poorer health status and sleep quality. These patients had a higher mean CAT score of 25.1 (vs. 16.2 for patients with mMRC $<2 ; \quad P<0.0001)$ and a mean JSEQ score of 7.1 (vs. 3.8 for patients with $\mathrm{mMRC}<2 ; \quad P<0.0001 ;$ Fig. 2). Patients with

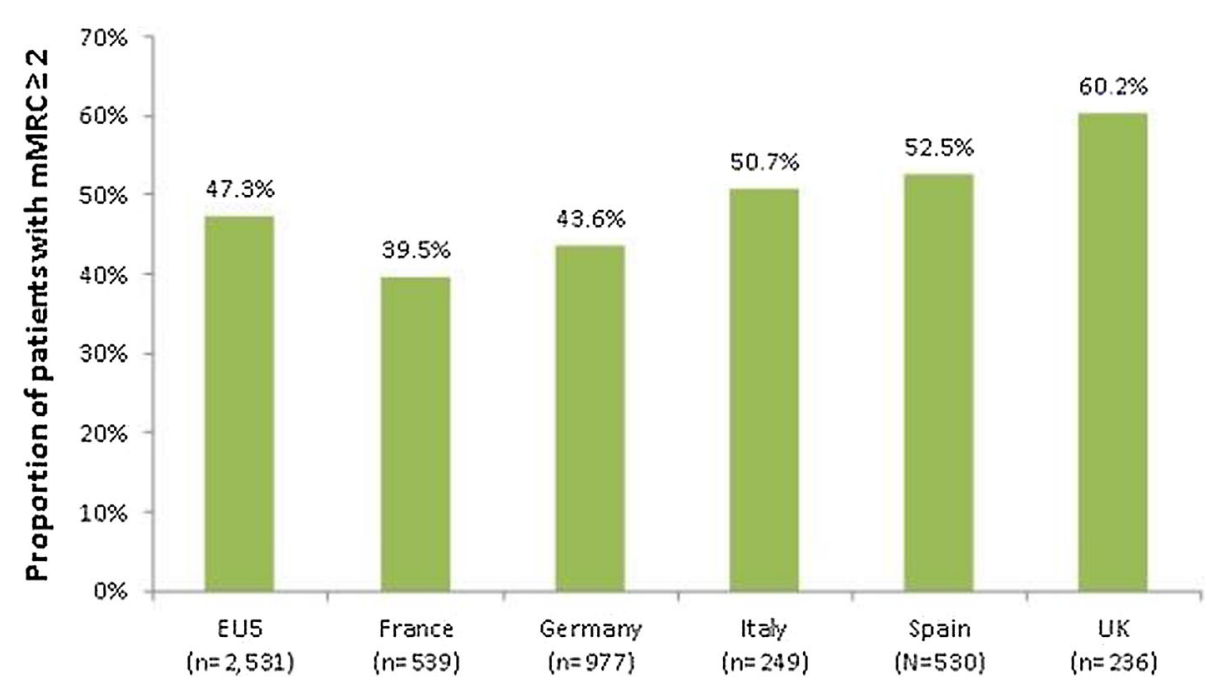

Fig. 1 Prevalence of dyspnoea among patients diagnosed with chronic obstructive pulmonary disease in the European countries studied. Percentages are based on

weighted data. EU5: France, Germany, Italy, Spain, and the UK. $m M R C$ Modified Medical Research Council dyspnoea scale 


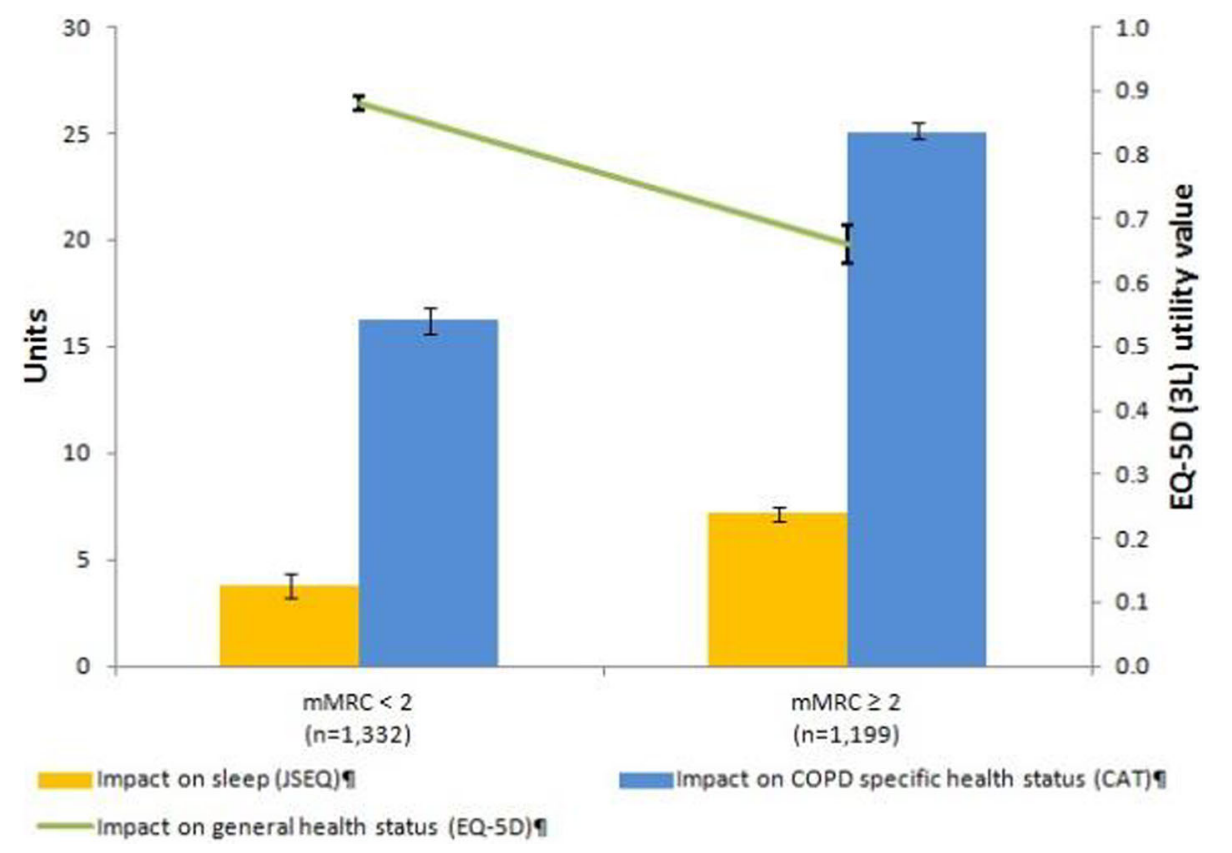

Fig. 2 Sleep and health status among patients with no-to-mild and moderate-to-severe dyspnoea at the time of survey. Values are based on weighted data. $\uparrow P<0.0001$. CAT COPD Assessment Test, COPD chronic obstructive

moderate-to-severe dyspnoea also had a significantly lower utility score of 0.66 compared to patients with $\mathrm{mMRC}<2$ (0.88; $P<0.0001)$. These observations were consistent across all countries surveyed (see Table S3 in the supplementary material).

\section{Association of Dyspnoea Level with HCRU}

Among the moderate-to-severe dyspnoeic patients, $597(50.6 \%)$ had at least one moderate exacerbation and 389 (34.7\%) had at least one severe exacerbation in the previous 12 months. The corresponding proportions for patients with no-to-mild dyspnoea were $30.0 \%$ and $9.5 \%$, respectively. In addition, higher proportions of patients in the moderate-to-severe dyspnoeic group had at least one emergency department visit leading to hospitalization $(26.1 \%$ vs. $5.8 \% ; P<0.0001)$ pulmonary disease, $E Q-5 D$-3L EuroQol Questionnaire (3 levels), JSEQ Jenkins Sleep Evaluation Questionnaire, $m M R C$ Modified Medical Research Council dyspnoea scale

or not leading to hospitalization $(14.7 \%$ vs. $3.9 \% ; P<0.0001)$ compared to patients with low dyspnoea. The exacerbation rates among these patients are displayed in Fig. 3.

Similar proportions of patients in both groups $(\mathrm{mMRC} \geq 2$ vs. $\mathrm{mMRC}<2$ ) had at least one PCP consultation $(84.6 \%$ vs. $85.7 \%$; $P=0.5898$ ) but higher proportions of moderate-to-severe dyspnoeic patients had at least one specialist consultation $(90.3 \%$ vs. 78.0\%; $\quad P<0.0001)$. The annual rate of physician consultation was higher among patients with moderate-to-severe dyspnoea, both for primary and secondary care consultations $(P<0.0001$ for both; Fig. 4). Moderate-to-severe dyspnoeic patients also had higher proportions of other HCRU, notably pulmonary rehabilitation, long-term oxygen therapy, and need for professional care (all $P<0.0001$; Table 2). 


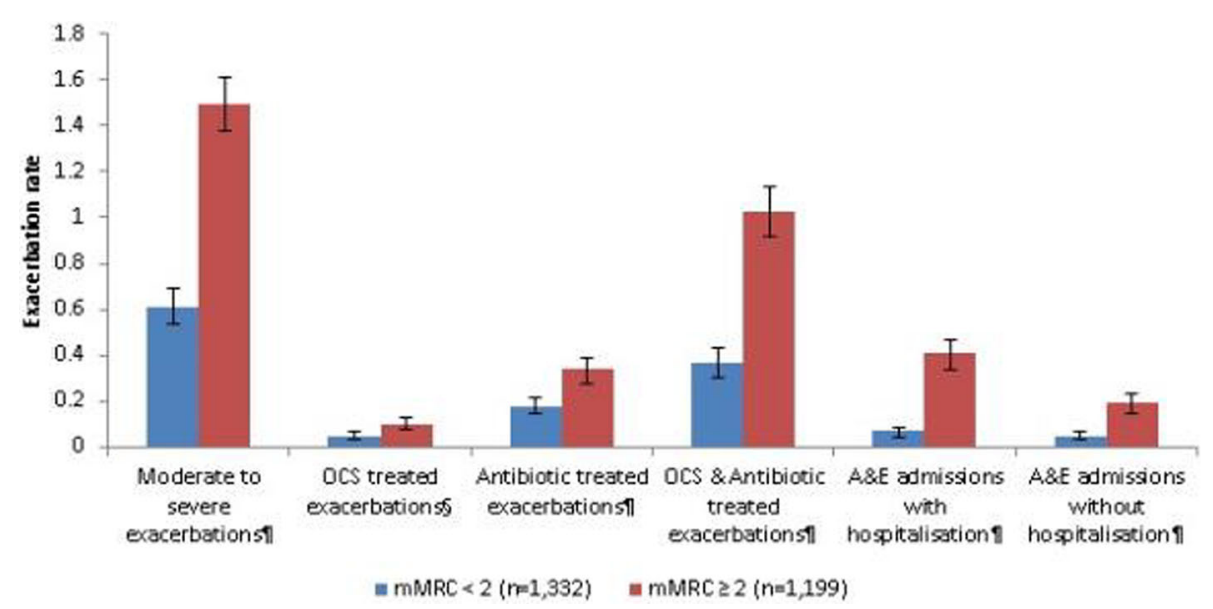

Fig. 3 Exacerbation rates in the previous year among unmatched no-to-mild and moderate-to-severe dyspnoea patients diagnosed with chronic obstructive pulmonary disease in the European countries studied. Rates based on weighted data. $\uparrow P<0.0001 ;{ }^{\S} P=0.0114$. $A \mho E$ Accident and emergency, OCS oral corticosteroids, $m M R C$ Modified Medical Research Council dyspnoea scale

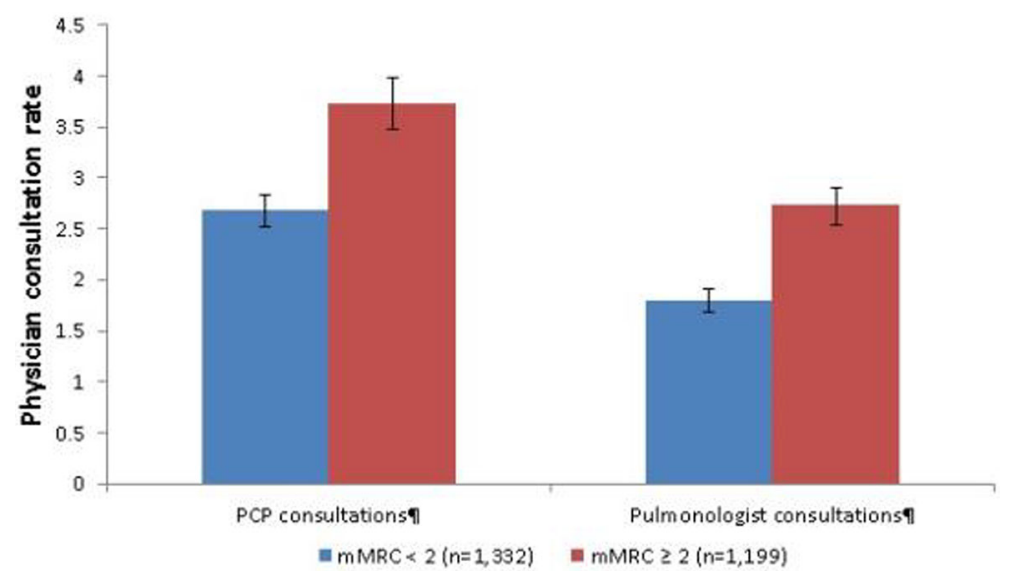

Fig. 4 Physician consultation rates in the previous year among unmatched no-to-mild and moderate-to-severe dyspnoea patients diagnosed with chronic obstructive pulmonary disease in the European countries studied.

\section{Association of Dyspnoea Level with COPD Management Costs}

Mean annual COPD management costs among the total sample irrespective of dyspnoea levels were $€ 2552$ [95\% confidence interval (CI): $€ 2267, € 2838]$. More than half the costs were related to exacerbations and hospitalizations $(€ 1569 ; 95 \% \mathrm{CI}: € 1354, € 1784)$ with the
Rates based on weighted data. $\Phi P<0.0001 . m M R C$ Modified Medical Research Council dyspnoea scale, PCP primary care physician

remaining distributed between medication costs ( $€ 409 ; 95 \% \mathrm{CI}: € 389, € 429)$, consultation costs (€301 (95\% CI: €282, €320), and other costs ( $€ 258$ (95\% CI: $€ 152, € 364)$.

In the full cohort, propensity matching on the baseline demographics and clinical parameters other than mMRC scores resulted in 762 patients with $\mathrm{mMRC} \geq 2$ and 762 matched patient profiles (400 unique patients) 
Table 2 Additional resource use in the previous 12 months

\begin{tabular}{lcc}
\hline Resource use, $\boldsymbol{n}(\%)^{\mathbf{a}}$ & mMRC $<2(\boldsymbol{n}=\mathbf{1 3 3 2})$ & mMRC $\geq 2(\boldsymbol{n}=\mathbf{1 1 9 9})$ \\
\hline Pulmonary rehabilitation $^{\mathrm{c}}$ & $104(8.9)$ & $188(17.8)$ \\
Vaccinations & $743(53.0)$ & $722(58.5)$ \\
Influenza $^{\mathrm{e}}$ & $511(39.6)$ & $578(48.0)$ \\
Pneumococcal $^{\mathrm{d}}$ & $0(0.0)$ & $1(0.3)$ \\
Lung transplantation $^{\mathrm{b}}$ & $1(0.0)$ & $5(0.3)$ \\
Lung volume reduction surgery $^{\mathrm{L}}$ & $24(1.8)$ & $139(11.3)$ \\
Long-term oxygen therapy $^{\mathrm{c}}$ & $2(0.1)$ & $50(4.3)$ \\
Professional care givers required $^{\mathrm{c}}$ &
\end{tabular}

$m M R C$ Modified Medical Research Council dyspnoea scale

a $n$ are unweighted data and \% are weighted data

b Available from the 2012 Respiratory Disease-Specific Programme data only

c $P<0.0001$

d $P<0.01$

e $P<0.05$

from a cohort of 919 available patients with mMRC $<2$. All covariates were adequately balanced post-matching (Table 1). In this propensity-matched cohort, the total annual COPD management cost was more than twofold higher among patients with moderate-to-severe dyspnoea compared to patients with no-to-mild dyspnoea ( $€ 4372$ vs. $€ 2031 ; P<0.0001)$. The sensitivity analysis produced a $\Gamma$ of 2.3 , which indicates the result is moderately insensitive to unobserved confounding factors. Although no statistical comparison was performed on individual cost components, patients with moderate-to-severe dyspnoea also showed higher costs of exacerbations and hospitalizations (€2898 vs. €1013), consultations (€432 vs. €306), and other costs ( $€ 556$ vs. $€ 235$ ). Medication costs in both groups were similar (€486 vs. €478). In the propensity-matched analyses of medication subgroups, the mean annual COPD management costs were higher in moderate-to-severe dyspnoeic patients compared to no-to-mild dyspnoeic patients in the mono-bronchodilator subgroup ( $€ 1945$ vs. $€ 910 ; \quad P=0.0112), \quad$ ICS/LABA fixed-dose combination subgroup (€3649 vs. $€ 633$; $P=0.0014)$ and triple therapy subgroup ( $€ 5766$ vs. $€ 2544 ; \quad P<0.0001 ; \quad$ Fig. 5). All covariates were adequately balanced in the subgroup analysis, except for time since diagnosis in the triple therapy subgroup $(\mathrm{SMD}=13.6 \%)$.

\section{DISCUSSION}

This study estimated the prevalence of dyspnoea among patients actively consulting due to their COPD, and its association with health status and costs in five European countries. Results showed that across all countries nearly half of the patients diagnosed with COPD suffered from moderate-to-severe dyspnoea. The moderate-to-severe dyspnoeic patients had worse general and COPD-related health status and impaired sleep compared to 


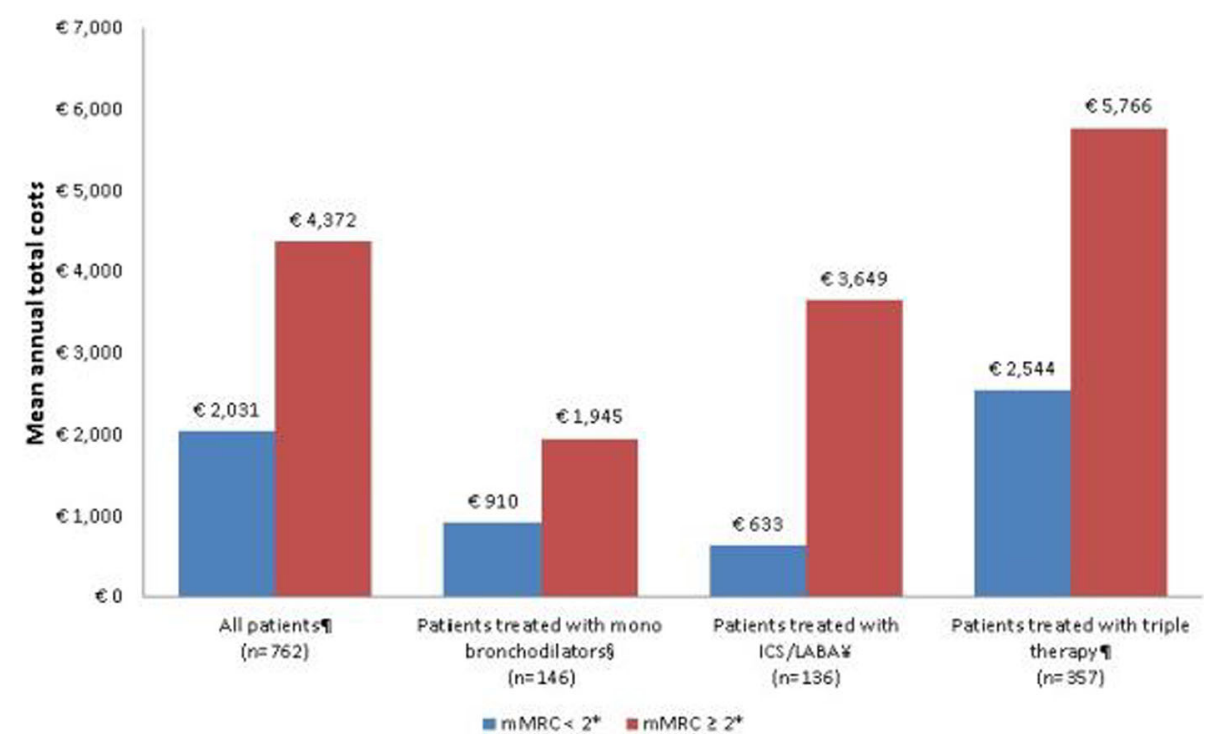

Fig. 5 Chronic obstructive pulmonary disease-related annual total costs in the propensity-matched patient cohorts with no-to-mild and moderate-to-severe dyspnoea and subgroups segmented by treatment type. $\uparrow P<0.0001$;

patients with no-to-mild dyspnoea. Dyspnoea is associated with higher HCRU and costs in most countries. The propensity-matched cohort analysis showed that patient-reported dyspnoea had a more than twofold increase in total costs in the previous year and may, therefore, remain at potential risk of increased future costs given the chronicity and progressive nature of COPD. As these findings remained after matching for baseline characteristics in patients with COPD irrespective of their COPD treatment including severity and cardiovascular comorbidity, this suggests that identification and better management of dyspnoeic patients with pharmacological and non-pharmacological interventions may improve their health status and potentially help local health economy in controlling COPD management costs.

Several studies have shown the level of dyspnoea has a significant impact on health status of patients with COPD. A study
${ }^{\S} P=0.0112 ;{ }^{¥} P=0.0014$. ${ }^{*}$ Propensity-matched sample where $n$ for ' $m M R C<2$ ' $=n$ for ' $m M R C \geq 2$ ' ICS inhaled corticosteroid, $L A B A$ long-acting $\beta$-agonist, $m M R C$ Modified Medical Research Council dyspnoea scale

conducted by Punekar and colleagues [40] using data from the respiratory DSP conducted in 2007 found EQ-5D-3L scores ranging from 0.88 [Medical Research Council (MRC) scale $=0$ ] to $0.17(\mathrm{MRC}=4)$ in a PCP cohort, and from 0.88 to 0.29 in a respiratory specialist cohort with differing levels of dyspnoea across the same five European countries reported here. The healthcare utilities in our study for the no-to-mild dyspnoeic patient group $(\mathrm{mMRC}<2)$ were identical at 0.88 but were substantially higher for patients with moderate-to-severe dyspnoea (mMRC $\geq 2 ; 0.17 / 0.29$ vs. 0.67 ). This may be attributable to differing definitions of moderate-to-severe dyspnoea in our study (mMRC $\geq 2)$ compared to the Punekar study $(\mathrm{mMRC}=4)$. Another study by Mullerova and colleagues [8] found that the presence of even mild dyspnoea (as compared to no dyspnoea) to be associated with more disease burden and higher frequency of comorbidities and a study by Kessler and others [4] found dyspnoea 
having significant impact on daily activities. Similarly, other studies have found dyspnoea to have a negative impact on CAT, SGRQ, and the 12-Item Short Form Health Survey (SF-12) physical component [41-43].

The Confronting COPD survey estimated the burden of COPD on patients globally [44]. The economic sub-analysis of confronting COPD survey indicated that costs ranged from $€ 590$ (direct cost: €395; indirect cost: €195) in patients with mild dyspnoea to $€ 4670$ (direct cost: €3036; indirect cost: $€ 1634)$ in patients with severe dyspnoea in the UK [44]. The corresponding costs ranged from $€ 441$ in patients with mild dyspnoea to €6365 in patients with severe dyspnoea in Italy [45]. In contrast, a retrospective database analysis of Clinical Practice Research Database conducted by Punekar and colleagues [46] estimated the costs in the range of $£ 1597-3579$ among patients with increasing levels of dyspnoea in the UK. The estimated costs in our study were comparable.

Our study has potential limitations. The sample collected was a convenience sample of consecutive eligible patients with COPD who actively consulted their physician; therefore, it may not fully represent the broad population of patients with COPD in the community in each country who may present less frequently to healthcare providers. However, the methodology does aim to remove any possible selection bias by removing any direct influence from the physician on the selection process. Moreover, the prevalence of dyspnoea and distribution of airflow limitation severity was similar to those observed in other studies conducted in general practice [43]. While minimal exclusion criteria governed the selection of physicians (mainly relating to the necessity of participating physicians to see a minimum volume of patients and be actively involved in patient management and treatment decisions), physician inclusion was likely influenced by their willingness to take part, and practical considerations of geographical location. These results were weighted to make them more generalizable to the COPD population in the specific country in which data were collected. In some instances, this resulted in negative CIs on costs due to an assumption of normality in calculating the 95\% CIs for right-skewed cost data.

The association of moderate-to-severe dyspnoea versus no-to-mild dyspnoea with HCRU has the limitation that the exposure (evaluation of dyspnoea via mMRC) comes after the outcomes being measured in the prior 12 months. However, our findings are in good agreement with prospective COPD populations studies in patients in Global initiative for chronic Obstructive Lung Disease (GOLD) groups A-D, which have shown moderate-to-severe breathlessness at entry is strongly associated with an increase in COPD- and non-COPD-related hospitalizations and future mortality [47, 48]. Moreover, mMRC grading captured prospectively or retrospectively at a point in time appears insensitive to short-term changes even when initiating or removing treatment and it is uncommon for population scores to alter by a fraction of a grade or individuals to improve or deteriorate by an entire grade in this period of follow-up $[49,50]$.

\section{CONCLUSIONS}

Dyspnoea is a highly prevalent symptom among patients with COPD recruited across multiple European countries. Moderate-to-severe dyspnoea presents significant humanistic burden on patients and is directly or indirectly associated with a high economic impact on the healthcare system. 


\section{ACKNOWLEDGMENTS}

Funding for this study HO-15-15223 and article processing charges were provided by GlaxoSmithKline. All named authors meet the International Committee of Medical Journal Editors (ICMJE) criteria for authorship for this manuscript, take responsibility for the integrity of the work as a whole, and have given final approval to the version to be published. Yogesh Suresh Punekar, Hana Mullerova, and Ian Naya contributed to the conception and design of the study. Mark Small, Tim Holbrook and Robert Wood contributed to data acquisition and analysis. All authors contributed to data interpretation and preparation of this manuscript.

Disclosures. Yogesh Suresh Punekar, Hana Mullerova, and Ian Naya are employees of GlaxoSmithKline and hold stocks at GlaxoSmithKline. Mark Small, Tim Holbrook, and Robert Wood are employed by Adelphi and were paid consultants to GlaxoSmithKline. Manuel Valle was a paid consultant to GlaxoSmithKline.

Compliance with Ethics Guidelines. The survey was conducted as a market research survey adhering to the ICC/ESOMAR international code on market and social research and, therefore, ethical approval was not sought. Prior to volunteering to complete a questionnaire, patients were asked to provide informed consent. The program instructions described the purpose of the survey, why the respondent had been selected, and who might have access to the aggregated and anonymized dataset compiled.

Open Access. This article is distributed under the terms of the Creative Commons
Attribution-NonCommercial 4.0 International License (http://creativecommons.org/licenses/ by-nc/4.0/), which permits any noncommercial use, distribution, and reproduction in any medium, provided you give appropriate credit to the original author(s) and the source, provide a link to the Creative Commons license, and indicate if changes were made.

\section{REFERENCES}

1. Global Initiative for Chronic Obstructive Lung Disease. Global Strategy for the diagnosis, management, and prevention of chronic obstructive pulmonary disease. Updated 2016. Available at http:/goldcopd.org/guidelines/ guidelines-resources.html. Accessed Jan 13, 2016.

2. NCD mortality and morbidity. Geneva: World Health Organization. Available from: http://www. who.int/gho/ncd/mortality_morbidity/en/. Accessed on Jan 13, 2016.

3. The top 10 causes of death. Geneva: World Health Organization. Available from URL: http://www. who.int/mediacentre/factsheets/fs310/en/. Accessed Jan 13, 2016.

4. Kessler R, Partridge MR, Miravitlles $M$, et al. Symptom variability in patients with severe COPD: a pan-European cross-sectional study. Eur Respir J. 2011;37:264-72.

5. Mollaoglu M, Fertelli TK, Tuncay FO. Fatigue and disability in elderly patients with chronic obstructive pulmonary disease (COPD). Arch Gerontol Geriatr. 2011;53:e93-8.

6. Punekar YS, Rodriguez-Roisin R, Sculpher M, Jones $\mathrm{P}$, Spencer M. Implications of chronic obstructive pulmonary disease (COPD) on patients' health status: a western view. Respir Med. 2007;101:661-9.

7. Hardie GE, Jonson S, Gold WM, Carrieri-Kolhman V, Boushey H. Ethnic differences: word descriptors used by African American and white asthma patients during induced bronchoconstriction. Chest. 2000;117:928-9.

8. Mullerova H, Lu C, Li H, Tabberer M. Prevalence and burden of breathlessness in patients with chronic obstructive pulmonary disease managed in primary care. PLoS ONE. 2014;9(1):e85540. doi:10.1371/journal.pone.0085540. 
9. Srivastava K, Thakur D, Sharma S, Punekar YS. Systematic review of humanistic and economic burden of symptomatic COPD. Pharmacoeconomics. 2015;33(5):467-88.

10. Anderson P, Benford M, Harris N, Karavali M, Piercy J. Real-world physician and patient behavior across countries: disease-Specific Programmes - a means to understand. Curr Med Res Opin. 2008;24(11):3063-72.

11. Charlson ME, Pompei P, Ales K, MacKenzie CR. A new method of classifying prognostic comorbidity in longitudinal studies: development and validation. J Chronic Dis. 1987;40(5):373-83.

12. Bestall J, Paul E, Garrod R, Garnham R, Jones P, Wedzicha J. Usefulness of the Medical Research Council (MRC) dyspnea scale as a measure of disability in patients with chronic obstructive pulmonary disease. Thorax. 1999;54(7):581-6.

13. Jones P, Harding G, Berry P, Wiklund I, Chen W-H, Kline Leidy N. Development and first validation of the COPD Assessment Test. Eur Respir J. 2009;34:648-54.

14. EuroQoL Group. EuroQoL-a new facility for the measurement of health-related quality of life. Health Policy. 1990;16(3):199-208.

15. Jenkins DC, Stanton B, Niemcryk SJ, et al. A scale for the estimation of sleep problems in clinical research. J Clin Epidemiol. 1988;41(4):313-21.

16. Morisky DE, Green LW, Levine DM. Concurrent and predictive validity of a self-reported measure of medication adherence. Med Care. 1986;24(1):67-74.

17. European Society for Opinion and Marketing Research (ESOMAR), International Code of Marketing and Social Research Practice 2007. http://ethics.iit.edu/ecodes/node/5178. Accessed Jan 13, 2016.

18. Torrance GW. Measurement of health state utilities for economic appraisal. J Health Econ. 1986;5:1-30.

19. Menn P, Heinrich J, Huber RM, et al. Direct medical costs of COPD - an excess cost approach based on two population-based studies. Respir Med. 2012;106(4):540-8.

20. Fédération Hospitalière de France. GACAH 2009. 2009 Available from: http://www.fhf.fr/Actualites/ Finances-BDHF/comptabilite-analytique/GACAH-20 09. Accessed Jan 13, 2016.

21. Ministero della Salute. Proposta metodologica per la valutazione dei costi dell'emergenza. 2007 Available from: http://www.mattoni.salute.gov.it/
mattoni/documenti/11_Valutazione_costi_dell_ emergenza.pdf. Accessed Jan 13, 2016.

22. Department of Health. NHS reference costs: financial year 2011 to 2012. 2012 Available from: https://www.gov.uk/government/publications/nhsreference-costs-financial-year-2011-to-2012. Accessed Jan 13, 2016.

23. Échantillon Généraliste de Bénéficiaires. 2014. Available from: http://www.iresp.net/iresp/files/ 2013/04/091020182511_pos093_echantillon_g.pdf. Accessed Jan 13, 2016.

24. Freytag A, Storz P, Hagenmeyer EG, et al. Direct cost of treatment of COPD in a German sickness fund. iHEA 6th World Congress, July 8-11, 2007, Copenhagen; 2007.

25. SDO. Rapporto annuale sull'attività di ricovero ospedaliero dati 2010. 2010. Available from: http://www.salute.gov.it/imgs/C_17_pubblicazioni_ 1690_allegato.pdf. Accessed Jan 13, 2016.

26. Garattini L, Castelnuovo E, Lanzeni D, Viscarra C, Gruppo di studio DYSCO VISITE. Durata e costo delle visite in medicina generale: il progetto. DYSCO. 4[2]. 2003.

27. PSSRU. Unit Costs of Health and Social Care 2012. 2012 Available from: http://www.pssru.ac.uk/ project-pages/unit-costs/2012/. Accessed Jan 13, 2016.

28. Agenzia Nazionale per i Servizi Sanitari Regionali. Tariffe delle prestazioni specialistiche ambulatoriali aggiornato al 31 dicembre 2009. Available from: http://www.agenas.it/monitoraggio_costi_tariffe/ 2009_SPECIALISTICA_ex\%20DM\%2096per\%20sito. pdf. Accessed Jan 13, 2016.

29. Murgia A, Scano G, Palange P, et al. Guidelines for long-term oxygen therapy. Update 2004. Rassegna Di Patologia Dell'Apparato Repiratorio. 2004;19:206-19.

30. Tarricone R, Lazzaro C. Valutazione degil aspetti economico-sanitari dell'ossigenoterapia domiciliare. 2003 Available from: http://www.gco.it/ Valutazione\%20degli\%20aspetti\%20economico\%20 sanitari\%20OTD.pdf. Accessed Jan 13, 2016.

31. Lucioni DC, Donner CF, De Benedetto F, et al. I costi della broncopneumopatia cronica ostruttiva in Italia. Presentazione della prima fase dello studio ICE (Italian Costs for Exacerbations in COPD). Pharmacoeconomics. 2005;7(2):119-34.

32. Department of Health. Consultation on a strategy for services for chronic obstructive pulmonary disease (COPD) in England. 2010 Available from: https://www.gov.uk/government/uploads/system/ 
uploads/attachment_data/file/213840/dh_113279. pdf. Accessed Jan 13, 2016.

33. Austin PC. An introduction to propensity score methods for reducing the effects of confounding in observational Studies. Multivariate Behav Res. 2011;46(3):399-424.

34. Abadie A, Imbens G. Large sample properties of matching estimators for average treatment effects. Econometrica. 2006;74(1):235-67.

35. Abadie A, Imbens G. Bias-corrected matching estimators for average treatment effects. J Bus Econ Stat. 2011;29:1.

36. Abadie A, Imbens G. On the failure of the bootstrap for matching estimators. Econometrica. 2008;76(6):1537-58.

37. Abadie A, Imbens G. Matching on the Estimated Propensity Score. 2012 National Bureau of Economic Research Working Paper No. 15301 available at http://www.hks.harvard.edu/fs/ aabadie/pscore.pdf. Accessed Jan 13, 2016.

38. Rosenbaum PR. Observational studies. Springer series in statistics; 2002. p. 1-17.

39. Craig R, Mindell J. Health survey for England 2013: Health, social care and lifestyles. Available at www. hscic.gov.uk/pubs/hse2013. Accessed Jan 13, 2016.

40. Punekar YS, Rodriguez-Roisin R, Sculpher M, Jones P, Spencer M. Implications of Chronic Obstructive Pulmonary Disease (COPD) on patients' health status: a western view. Respir Med. 2007;101(3):661-9.

41. Voll-Aanerud M, Eagana TML, Wentzel-Larsenb T, Gulsvikc A, Bakkea PS. Respiratory symptoms, COPD severity, and health related quality of life in a general population sample. Respir Med. 2008;102:399-406.

42. Jones P, Adamek L, Nadeau G, Banik N. Comparisons of health status scores with MRC grades in a primary care COPD population: implications for the new GOLD 2011 classification. Eur Respir J. 2013;42(3):647-54.

43. Jones P, Brusselle G, Dal Negro R, Ferrer M, Kardos $P$, Levy $M$, et al. Patient-centred assessment of COPD in primary care: experience from a cross-sectional study of health-related quality of life in Europe. Prim Care Respir J. 2012;21:329-36.

44. Britton M. The burden of COPD in the UK: Results from the confronting COPD survey. Respir Med. 2003;97(SUPPL. C):S71-9.

45. Dal Negro R, Rossi A, Cerveri I. The burden of COPD in Italy: results from the Confronting COPD survey. Respir Med. 2003;97(SUPPL. C):S43-50.

46. Punekar YS, Shukla A, Muellerova H. COPD management costs according to the frequency of COPD exacerbations in the UK primary care. Int $\mathrm{J}$ Chron Obstruct Pulomn Dis. 2014;9(1):65-73.

47. Agusti A, Edwards LD, Celli B, Macnee W, Calverley PM, Müllerova $\mathrm{H}$, et al. Characteristics, stability and outcomes of the 2011 GOLD COPD groups in the ECLIPSE cohort. Eur Respir J. 2013;42(3):636-46.

48. Lange P, Marott JL, Vestbo J, Olsen KR, Ingebrigtsen TS, Dahl M, et al. Prediction of the clinical course of chronic obstructive pulmonary disease, using the new GOLD classification: a study of the general population. Am J Respir Crit Care Med. 2012;186(10):975-81.

49. Magnussen H, Disse B, Rodriguez-Roisin R, Kirsten A, Watz H, Tetzlaff K, et al. Withdrawal of inhaled glucocorticoids and exacerbations of COPD. N Engl J Med. 2014;371(14):1285-94.

50. Punekar YS, Landis SH, Wurst K, Le H. Characteristics, disease burden and costs of COPD patients in the two years following initiation of long-acting bronchodilators in UK primary care. Respir Res. 2015;16:141. 